\title{
EL VERDADERO AMOR MANIFESTADO EN LA RELACIÓN CONYUGAL
}

Rodríguez Luque, Álvaro F. Facultad de Teología

Universidad Peruana Unión alfer.rodriguez@teologia.edu.pe

Fecha de recepción: Agosto 2012

Fecha de aceptación y versión final: Septiembre 2012

El presente artículo tiene el objetivo de establecer algunas formas de mantener el amor en una pareja de esposos, basándose en las enseñanzas de la Biblia y del Espiritu de Profecía. Para tal propósito se hará una breve definición de lo que es el amor y lo que éste implica para asi establecer formas biblicas, y por lo tanto correctas, que permitan fortalecer las relaciones amorosas entre los esposos. Luego se presentarán una serie de actitudes y actividades para el fortalecimiento de la relación amorosa de los cónyuges, fundamentadas en estudios realizados sobre el matrimonio y el divorcio.

Palabras clave: Matrimonio, divorcio, amor. respeto. 


\section{Definición y naturaleza del amor}

¿Qué es el amor? Pregunta poco fácil de responder. El amor es una expresión del ser humano que generalmente se deriva del sentimiento y el gusto de una persona por aquello que dice amar. Pero tal definición no es plena. Es verdad que el amor implica sentimientos, pero no lo es todo. Los sentimientos pueden variar, dependiendo de la persona, en el tiempo. Por ejemplo, alguien puede decir "me gustan los helados", pero es posible que en poco tiempo ya no sea así. La razón del cambio de gusto es variada, pero se fundamenta en los sentidos que los seres humanos poseen.

Existen dos definiciones muy interesantes en relación al amor. Una es tomada de la Biblia y la otra del Espíritu de Profecía. La Biblia declara que "Dios es amor"1 (1 Jn 4:8). Esta declaración no define el amor sino que permite comprender cuál es la fuente del amor, a saber, Dios. Por su parte, el Espíritu de Profecía sostiene lo siguiente: "El

11 Juan 4:8. Para el presente artículo, se usará la versión castellana La Biblia de las Américas (LBLA). amor es un precioso don que recibimos de Jesús. El afecto puro y santo no es un sentimiento, sino un principio". ${ }^{2}$ Esta cita confirma lo que el texto bíblico propone y agrega que el amor "no es un sentimiento, sino un principio".

Hasta aquí se ha podido determinar dos elementos. Primero, la naturaleza del amor. Es posible afirmar que el amor tiene un origen sobrenatural, pues es un don que viene de Dios. El verdadero amor solo puede provenir de la verdadera fuente del amor. Esto significa que solamente Dios es capaz de amar en forma perfecta y plena. Es por eso que, a través del profeta, el propio Dios declara: "Con amor eterno te he amado". ${ }^{3}$ Solo Dios es eterno, por tanto solo Él puede amar eternamente. Ahora bien, si solo un amor eterno es verdadero, entonces solo Dios es capaz de amar con un amor verdadero.

Si bien es cierto que solo Dios puede dar amor real, es necesario reconocer también que el ser humano puede reflejar el

2 Elena G. White, El ministerio de curación (Buenos Aires: Asociación Casa Editora Sudamericana, 2008), 276.

3 Jeremías 31:3, LBLA. 
amor de Dios en sus relaciones interpersonales. Por lo tanto, aunque el amor que se profesan dos seres humanos es propenso al error, imperfecto ${ }^{4}$ y muchas veces inadecuado ${ }^{5}$; no hay razón para desistir de una relación de amor entre dos seres humanos, varón y mujer, que se han unido en santo matrimonio. Aunque el relacionamiento sea imperfecto, puede perfeccionarse si el esposo y la esposa mantienen como prioridad un íntimo relacionamiento con Dios, que es la única fuente del amor verdadero.

4 El ser humano no puede amar en forma perfecta por el hecho de ser imperfecto y de naturaleza pecaminosa (Ro 3:10-18, Sal 51:5). De hecho, todo lo tiene un origen humano es imperfecto. Esta realidad se puede percibir en la siguiente declaración de Elena G. White: "Si nosotros imitáramos el ejemplo de cualquier hombre -aun el de una persona a quien, a juicio nuestro, consideráramos casi perfecta de carácter- estaríamos poniendo nuestra confianza en un ser humano imperfecto y defectuoso..., Mente, carácter y personalidad (Buenos Aires: Asociación Casa Editora Sudamericana, 1990), 2:736.

5 Que haya un amor inadecuado se puede notar en la vida de un gran número de parejas que establecen relaciones amorosas, incluso llegando hasta el matrimonio, y terminando en diversas formas de violencia intrafamiliar que desencadenan múltiples desórdenes personales y familiares, hasta llegar, en muchos casos, al divorcio.
Siendo que se ha establecido claramente el origen celestial del amor, ahora veremos la definición del amor. Es posible definirlo inicialmente como una cualidad o característica de Dios (cf. 1 Jn 4:8). Pero es necesario ir un poco más allá de esto. Toda cualidad divina tiene su propia manifestación. Es aquí donde el espíritu de profecía ayuda a definir el amor. Recurriendo a la cita mencionada anteriormente, se puede afirmar que el amor no es un sentimiento sino un principio. Según la Real Academia de la Lengua un principio es "norma o idea fundamental que rige el pensamiento o la conducta". ${ }^{6}$ Entonces el amor es una norma fundamental que rige algo. En el caso de la relación conyugal, el amor será una norma fundamental que rige la relación entre esposos.

En otra cita del Espíritu de Profecía se puede leer lo siguiente:

El amor debe ser el principio que impulse a obrar. El amor es el principio fundamental del gobierno de Dios en los cielos $y$ en la tierra, y debe ser el fundamento del carácter del cristia-

6 Real Academia de la Lengua Española, Diccionario de la lengua española, 22da ed. (Madrid: Editorial Espasa Calpe, 2001), s.v. "principio". 
no. Solo este elemento puede hacer estable al cristiano. Solo esto puede habilitarlo para resistir la prueba y la tentación. ${ }^{7}$

Por lo que se puede notar en esta cita, el amor es el principio fundamental del gobierno de Dios. Es decir, Dios gobierna teniendo como fundamento el amor. Al mismo tiempo, este amor es el que impulsa o mueve a Dios en su accionar. La creación del mundo (Gn 1-2), el diluvio (Gn 6-8), la liberación de su pueblo cuando estuvo en Egipto (Éx 12), el cruce del mar Rojo (Éx 14), la entrega de los diez mandamientos en el Sinaí (Éx 19-20), la posesión de la tierra prometida (Jos 3-6), la vida, muerte y resurrección de Jesús (Jn 3:16), entre otros, todos fueron actos de Dios motivados por su amor a la raza humana, a pesar de su condición de pecado.

Es el propósito de Dios que todo cristiano, seguidor fiel de la voluntad de Dios plasmada en la Santa Biblia, tenga el amor como base de sus relaciones interpersonales. Es decir, su motivación debe ser, el amor que solo proviene de Él. Es este fun-

7 Elena G. White, Consejos sobre mayordomía cristiana (California: $\mathrm{Pu}-$ blicaciones Interamericanas, 1971), 207. damento de origen celestial lo que provee de estabilidad al ser humano que confía en Dios. La sociedad actual se mueve en base a todo tipo de "filosofías y vanas sutilezas" (Colosenses $2: 8)$, y son estos endebles fundamentos los que han construido una sociedad cambiante e inestable, que ha provocado repercusiones negativas, incluso en la institución llamada familia ${ }^{8}$ y en la relación conyugal. ${ }^{9}$

Siendo que el fundamento del gobierno de Dios es el amor. Es necesario echar un vistazo a otra cita que permite entender

8 Se debe considerar que la familia es una institución establecida desde la fundación del mundo, en la creación, teniendo como Juez a Dios mismo. Tal evento sanciona el matrimonio como una institución celestial e indisoluble, salvo ciertos vicios que rompan el pacto de amor que se realiza entre la pareja (Gn 2:23-25; cf. Mt 19:1-9).

9 Se debe admitir que la familia pasa por varias crisis durante su desarrollo, unas más fuertes que otras y éstas no necesariamente son negativas o positivas, véase Idarmis Gonzales Benitez, "Las crisis familiares", Revista Cubana de Medicina General Integral 16, no. 3 (2000): 280. Es interesante que esta realidad es percibida por estudiosos de derecho, en la que se percibe que el matrimonio se ha convertido en un asunto de un contrato común y corriente, véase Luigi Balestra, "Autonomía negocial y crisis conyugal: Los acuerdos en vista de la futura separación", Revista de Derecho 6 (2005): 173. 
cómo es que el amor de Dios se ha manifestado en favor de la raza humana y cómo éste sirve como un principio de gobierno:

"La ley de Dios es una expresión de su misma naturaleza; es la personificación del gran principio del amor y, en consecuencia, el fundamento de su gobierno en los cielos y en la tierra". ${ }^{10}$

Por lo tanto, la obediencia a Ley de Dios que expresa la voluntad divina es la máxima expresión de Su carácter y gobierno.

A manera de conclusión de esta primera parte, se puede establecer que el amor viene de Dios y que se manifiesta en forma expresa en la Ley de los Diez Mandamientos. Por su parte, el ser humano no puede manifestar dicho amor a menos que se ponga en sintonía con Dios que es la única fuente del amor verdadero. Para que el ser humano ame con amor verdadero, es necesario que mantenga una íntima relación con Dios, que acepte el sacrificio de Cristo en su favor y que permita la presencia del Espíritu Santo en su vida, pues el amor que viene de Dios

10 Elena G. White, El camino a Cristo (Buenos Aires: Asociación Casa Editora Sudamericana, 2008), 59-60. es fruto del Espíritu Santo (Gá $5: 22)$.

\section{Mantenimiento del amor conyugal}

Según algunas investigaciones sobre las razones que desencadenan un divorcio, existe una serie de factores que intervienen en detrimento de las relaciones conyugales. Un estudio realizado en Uruguay sugiere que "el riesgo de divorcio se ve aumentado por la existencia de un periodo de cohabitación".11 Por otro lado, se ha detectado que existe también un "alto riesgo de divorcio en las parejas sin hijos". ${ }^{12}$ También se ha detectado que el hecho de contraer matrimonio a una edad temprana, especialmente en la adolescencia, contiene mayores riesgos de divorcio en una pareja. ${ }^{13}$ Finalmente, se ha encontrado que a mayor nivel de privación en relación a bienes obtenidos por la pareja, entonces el riesgo de divorcio es mayor. ${ }^{14}$

11 Marisa Bucheli y Andrés Vigna, "Un estudio de los determinantes del divorcio en Uruguay", Desarrollo y Sociedad 56 (2005): 16.

12 Ibíd., 15.

13 Ibíd., 16.

14 Ibíd., 18. Esto no significa que el nivel socioeconómico sea un factor de 
En otro estudio en el que se compara a los países grandes, Estados Unidos y China, que a su vez tienen el más alto y más bajo promedio de divorcios respectivamente, se han encontrado algunas similitudes que permiten establecer razones universales sobre las causales de los divorcios. ${ }^{15}$ Entre los factores de riesgo similares se encontró lo siguiente: ${ }^{16}$ La mayoría de divorcios se dan sobre los 30 años. El tiempo previo al matrimonio, entre el conocerse y el matrimonio es un tiempo muy corto. Los divorcios suceden antes de los 5 años de matrimonio. El divorcio en ambos países se intensifica cuando se tienen hijos.

Frente a estos datos es tiempo ahora de meditar en vuestro matrimonio. Es posible que usted, con su pareja, haya tenido un tiempo de convivencia previo a su matrimonio o que el período de noviazgo haya sido muy corto. Es posible que su matrimonio no lleve más de cinco años y se haya realizado en su adolescencia. Eso significa que tiene

riesgo de divorcio, sino el grado de satisfacción (en cuanto al factor económico) que se presenta en la pareja.

15 Pang Linlin, "Divorce in United States vs. in China", Journal of Popular Culture 27 no. 2 (1993): 91.

16 Ibíd., 91 un mayor riesgo de divorcio. Esto no exime a aquellas parejas que tienen más de cinco años de casados y que se casaron a una edad madura luego de un periodo razonable de noviazgo. En tal caso, el riesgo de divorcio no es alto, pero existe. Esto se debe a que como seres humanos, podemos fallar en cualquier momento y eso llevará, en algunos casos, inevitablemente al divorcio.

A continuación se presentarán una serie de elementos que deben tenerse en cuenta para disminuir cada vez más el riesgo de divorcio. Básicamente, se trata de incrementar el nivel de satisfacción dentro del matrimonio y fortalecer el amor que se prometieron como pareja aquel día feliz en que los declararon marido y mujer.

\section{El amor es una decisión}

Hay que tener en cuenta que el amor no es solamente un sentimiento, ${ }^{17}$ el amor es "un acto de la voluntad" humana. ${ }^{18}$

Por lo tanto, el amor es una decisión y los sentimientos que

17 White, El ministerio de curación, 276.

18 Marí Isabel Irarrázabal, "El divorcio: Una discusión gravitante", $\mathrm{Hu}$ manitas 24 (2001): 652. 
se expresan son la manifestación de dicha decisión. ${ }^{19}$ Esto es el fundamento para las relaciones de pareja. Es justamente esto lo que diferencia el amor de un sentimiento. Cuando uno decide, debe ser consciente de la envergadura de tal decisión y la responsabilidad que ésta conlleva.

La decisión de amar debe basarse en el fundamento del amor de Dios. Si en la decisión del matrimonio no se consideran estos dos elementos, entonces tal medida será fuente de desdicha. Considere el amor de Dios. La fuente del verdadero amor, como se ha visto anteriormente, no está en el ser humano, sino que solo viene de Dios. En tal sentido, es necesario considerar las características del amor de Dios.

La primera característica es la incondicionalidad del amor de Dios por el ser humano. Esta característica se puede notar en Juan 3:16 que dice: "Porque de tal manera amó Dios al mundo, que dio a su Hijo unigénito, para que todo aquel que cree en Él, no se pierda, mas tenga vida

19 Miguel Ángel Núñez, $A$ amar se aprende, 5ta. ed. (Lima, Perú: Ediciones Fortaleza, 2007), 35. eterna”. El Padre, sabiendo que Cristo sería despreciado por la raza humana, pudo dejar al ser humano abandonado a su triste destino, pero envió a su Hijo. El plan de salvación en favor del hombre se llevó a cabo a pesar de la indiferencia y el mayoritario rechazo de la raza humana.

En segundo lugar el amor de Dios es inmutable. A lo largo de las Escrituras, el amor de Dios se ha manifestado en favor de la raza humana, a pesar de su continua conducta rebelde contra Dios. Adán y Eva permitieron que el pecado se instaurara en su raza, luego Caín hizo lo suyo, vino más adelante el diluvio y la torre de Babel. Posteriormente encontramos al pueblo de Israel, que luego de ser librado del yugo de Egipto se apartaba constantemente de Dios. Aun así, Dios permanece fiel a su palabra y a sus promesas. Estando en la tierra prometida, los descendientes de Israel se apartaron hacia los falsos dioses, pero el Señor enviaba a sus profetas para restaurar la adoración al Dios verdadero, todo esto lo hizo por amor. De allí que el profeta declare de parte de Dios: "Con amor eterno te he amado, por eso te he atraído con misericordia”. ${ }^{20}$ En

20 Jeremías 31:3 
tercer lugar, el amor de Dios, por su inmutabilidad, es perdonador. El perdón es parte de la manifestación del amor que viene del cielo. En muchas ocasiones el Señor ha perdonado a su pueblo. Lo hizo con Abraham, con Jacob, con David. Un caso interesante es el del apóstol Pedro. Luego de que lo negara por tercera vez, Cristo lo miró y lo amó. Luego el seguidor de Cristo se arrepintió de corazón, unos días más tarde Cristo le pregunta: "Jesús dijo a Simón Pedro: Simón, hijo de Jonás, ¿me amas más que éstos?". ${ }^{21}$ Esta pregunta se repitió tres veces para mostrarle que el perdón es más grande que el pecado.

Estas tres características fundamentales del amor de Dios deben manifestarse también en la dinámica conyugal. En la vida cotidiana, en la pareja se manifiestan toda clase de actitudes, muchas de ellas son positivas, pero existen también actitudes negativas que pueden provocar conflictos y desavenencias entre esposos. Se debe recordar que el amor de la pareja, debe ser en cierta manera el reflejo del amor de Dios por la humanidad. De hecho, en la Biblia el amor de

21 Juan 21:15.
Dios es ilustrado a través de la relación conyugal (Ez 16:8-14, cf. Os 2:19-20).

Por lo tanto, en una relación de esposos, debe primar el amor como una decisión. Este amor debe ser incondicional, inmutable y perdonador. Hacer esto en el hogar permitirá un hogar de dicha. Del mismo modo permitirá relaciones afectivas saludables.

\section{El amor es acción}

El amor no es un estado emocional, sino que debe ser el fundamento de las acciones en el hogar. Considere la siguiente cita del Espiritu de profecía:

Cuando el principio celestial del amor eterno llena el corazón, éste fluye hacia otros, no por el hecho de que se reciba de otros sino porque el amor es el principio de acción y modifica el carácter, gobierna los impulsos, controla las pasiones, subyuga la enemistad y eleva y ennoblece los afectos. ${ }^{22}$

22 Elena G. White, Testimonies for the Church (Mountain View, CA: Pacific Press, 1948), 4:223. La traducción del inglés al español es personal. Si bien la cita no está dada en el contexto del matrimonio o la pareja, sí expresa la esencia de lo que es el amor de Dios cuando es aceptado por el ser humano y sus resultados. Éstos pueden aplicarse a todos los 
Se puede notar que el amor celestial es un principio de acción. El amor no paraliza a las personas, al contrario, las lleva a la acción. Si existe verdadero amor en una relación conyugal, éste debe llevar a la acción. El amor no solo debe ser profesado, también debe ser manifestado. Retomando Juan 3:16, se puede afirmar que el amor de Dios fue el motivo principal para que el plan de salvación se ejecute. Por amor, Cristo se hizo hombre y se entregó por nosotros. El verdadero amor es acción en favor del otro.

Una relación de pareja, donde los esposos no hacen nada para fortalecer el amor entre ellos, está condenada a la desdicha e incluso al divorcio. El amor hay que demostrarlo a través de actos en favor de quien se ama. Esto se puede ilustrar con una metáfora: La cuenta bancaria emocional. ${ }^{23}$ Esta metáfora sugiere que para fortalecer la relación matrimonial, es necesario hacer depósitos en la cuenta emocional, aunque en ocasiones se hagan retiros. Lo que se

ámbitos de la vida.

23 Esta metáfora ha sido tomada de Fernando Zabala, A pesar de nuestras diferencias... Me casaría de nuevo contigo (Buenos Aires: Asociación Casa Editora Sudamericana, 2010), 160-6. debe tener en cuenta es que una actitud o conducta, en algunas ocasiones, puede ser contada como un depósito, mientras que en otras, puede ser un retiro.

En esta cuenta emocional, no basta con hacer algo en favor de la relación, también es necesario examinar la intención con la cual se hace. Es posible otorgar un ramo de rosas a la esposa, pero, por las condiciones del matrimonio, en ciertas ocasiones, puede ser tomado como una burla, por lo tanto no es favorable. El objetivo es mantener la cuenta con saldo a favor. Si como pareja se logra esto, entonces la relación conyugal será positiva y crecerá cada día más.

\section{Conclusión}

Ahora el turno es de usted, querido lector. Le toca a usted tomar parte activa en favor de su matrimonio. Decida amar a su pareja, perdone y comience a hacer depósitos en su cuenta emocional para el beneficio de su relación. Solamente usted sabe lo que tiene que hacer para fortalecer su matrimonio. Es usted quien conoce a su cónyuge y sabe qué es lo que le agrada y lo que espera de usted. Póngase 
en acción, no lo deje para más adelante y recuerde que el amor de Dios es el que debe guiar sus decisiones.

\section{Bibliografía}

Balestra, Luigi. "Autonomía negocial y crisis conyugal: Los acuerdos en vista de la futura separación", Revista de Derecho 6 (2005): 173-93.

Bucheli, Marisa y Andrés Vigna. "Un estudio de los determinantes del divorcio en Uruguay", Desarrollo y Sociedad 56 (2005): 1-21.

Diccionario de la lengua española, 22 da ed. Madrid: Editorial Espasa Calpe, 2001.

Gonzales Benitez, Idarmis. "Las crisis familiares", Revista Cubana de Medicina General Integral 16, no. 3 (2000): 280-6.

Irarrázabal, Mari Isabel. "El divorcio: Una discusión gravitante", Humanitas 24 (2001): 651-6.

Linlin, Pang. "Divorce in United States vs. in China", Journal of Popular Culture 27 no. 2 (1993): 91-99.

Núñez, Miguel Ángel. A amar se aprende, 5ta. edición. Lima, Perú: Ediciones Fortaleza, 2007.

White, Elena G. Consejos sobre mayordomia cristiana. California: Publicaciones Interamericanas, 1971.

El camino a Cristo. Buenos Aires: Asociación Casa Editora Sudamericana, 2008.

El ministerio de curación. Buenos Aires: Asociación Casa Editora Sudamericana, 2008.

. Mente, carácter y personalidad. Buenos Aires: Asociación Casa Editora Sudamericana, 1990.

Testimonies for the Church. Mountain View, CA: Pacific Press, 1948. Zabala, Fernando. A pesar de nuestras diferencias... Me casaría de nuevo contigo. Buenos Aires: Asociación Casa Editora Sudamericana, 2010. 